Pure Appl. Chem., Vol. 74, No. 5, pp. 787-791, 2002.

(C) 2002 IUPAC

INTERNATIONAL UNION OF PURE AND APPLIED CHEMISTRY

INORGANIC CHEMISTRY DIVISION

COMMISSION ON NOMENCLATURE OF INORGANIC CHEMISTRY*

\title{
NAMING OF NEW ELEMENTS
}

\section{(IUPAC Recommendations 2002)}

\author{
Prepared for publication by \\ W. H. KOPPENOL \\ Laboratorium für Anorganische Chemie, Eidgenössische Technische Hochschule, CH-8093 Zürich, \\ Switzerland
}

*Membership of the Commission during the preparation of this report (1997-2001) was as follows:

Titular Members: A. Sargeson (Chairman, 1987-1997); H. Kaesz (Chairman, 1998-2001); W. H. Koppenol (Secretary, 1994-1997); C. A. Stewart (Secretary, 1998-1999); T. Damhus (Secretary, 2000-2001); M. W. G. de Bolster (1987-1997); N. Connelly (1998-2001); T. Damhus (1998-2001); A. Dress (1996-2001); R. M. Hartshorn (2000-2001); A. T. Hutton (2000-2001); H. Kaesz (1994-2001) A. Salzer (1991-1999); C. A. Stewart (1996-1999); Associate Members: G. Bergerhoff (1991-1997); J. B. Casey (1992-2001); J. de Oliveira Cabral (1994-1997); P. Royo Gracia (1994-2001); Y. Yamamoto (1996-2001); National Representatives: M. A. Bennett (Australia, 1992-2001); R. Bhattacharyya (India, 1998-2001); J. Cernak (Slovakia, 2000-2001); C. S. Chin (Korea, 1992-2001); N. Coville (South Africa, 1998-2000); L. I. Elding (Sweden, 1994-1999); C. A. L. Filgueiras (Brazil, 1998-2001); P. Fodor-Csányi (Hungary, 1991-2001); E. W. Godly (UK, 1987-1997); A. T. Hutton (South Africa, 2001); V. Kolotov (Russia, 1994-1997); N. Külcü (Turkey, 2000-2001); R. S. Laitinen (Finland, 1994-2001); K. Mackay (New Zealand, 1987-1999); D. Meyerstein (Israel, 1994-2001); H. Nakazawa (Japan, 1996-1999); E. Nordlander (Sweden, 2000-2001); F. P. Pruchnik (Poland, 1998-2001); J. Reedijk (Netherlands, 1987-1999); M. Zulu (South Africa, 1989-1997).

Republication or reproduction of this report or its storage and/or dissemination by electronic means is permitted without the need for formal IUPAC permission on condition that an acknowledgment, with full reference to the source, along with use of the copyright symbol $\odot$, the name IUPAC, and the year of publication, are prominently visible. Publication of a translation into another language is subject to the additional condition of prior approval from the relevant IUPAC National Adhering Organization. 


\title{
Naming of new elements
}

\section{(IUPAC Recommendations 2002)}

\begin{abstract}
A procedure is proposed to name new elements. After the discovery of a new element is established by a joint IUPAC-IUPAP Working Group, the discoverers are invited to propose a name and a symbol to the IUPAC Inorganic Chemistry Division. Elements can be named after a mythological concept, a mineral, a place or country, a property, or a scientist. After examination and acceptance by the Inorganic Chemistry Division, the proposal follows the accepted IUPAC procedure and is then submitted to the IUPAC Council for approval.
\end{abstract}

\section{CONTENTS}

1. INTRODUCTION

2. EXISTING RECOMMENDATIONS

3. CHOICE OF NAMES FOR NEW ELEMENTS

4. PROCEDURE FOR NAMING A NEW ELEMENT

4.1 Formal proposal of a name

4.2 Examination by the Inorganic Chemistry Division and public review

4.3 Formal naming of the element

4.4 Interim names

\section{INTRODUCTION}

As early as 1782 it was stated by Guyton de Morveau that, in the interest of science, it was necessary to have "a constant method of denomination, which helps the intelligence and relieves the memory" [1]. Ideally, an element or a compound should have a unique name because the proliferation of names for the same substance can lead to confusion.

A case in point, but not the only one, is element 104, for which the names rutherfordium and kurchatovium have been used for nearly three decades by competing laboratories. At the heart of the problem is the belief of the discoverers that they have the sole right to name a new element. However, given a decision by IUPAC in 1947, discoverers have the right to suggest a name to IUPAC, but only the IUPAC Commission on Nomenclature of Inorganic Chemistry, after an examination of the suggested name to determine its suitability and a public and expert review process, could make a recommendation to the IUPAC Council. On 1 January 2002, when the IUPAC Commission on the Nomenclature of Inorganic Chemistry ceased to exist, this responsibility was taken over by the IUPAC Inorganic Chemistry Division to which this Commission belonged. The IUPAC Council makes the final decision (see below).

While the origin of the names of some elements is obscure, the names of others have been based on a property of the element, a mineral from which it was isolated, its place or area of discovery, a mythological character or concept, an astronomical object, or were proposed to honor an eminent scientist.

\section{EXISTING RECOMMENDATIONS}

The recent debate on the naming of the transfermium elements has centered on three issues: (1) priority of discovery, (2) the right of discoverers to suggest names, and (3) the role of the IUPAC 
Commission on Nomenclature of Inorganic Chemistry. These issues were first addressed in 1947, as discussed in ref. [2]:

It was decided at the 1947 conference of the International Union of Chemistry, held in London, that in the future the naming of elements and all questions relating to the names and symbols of the elements should be dealt with by joint meetings of the Commissions of Inorganic Nomenclature and of Atomic Weights. Such matters had previously been dealt with by the Commission of Atomic Weights alone.

It has been accepted in the past that the discoverers of a new element had the sole right to name it. Sometimes two different names have been given for the same element at about the same time and now it is often difficult to decide which was actually given first. Moreover, a name which was given later in point of time may have come into more general use or be more suitable than the name first given and there are cases of this kind in the International Table of Atomic Weights, so that the acceptance of a given name for an element must not be regarded as bearing any claim to priority of discovery. Priority is only one factor to be considered in deciding which is the best name for general international adoption. This presumptive right to name new elements is now accorded to the discoverers of new elements produced artificially, but subject to the approval of the Nomenclature Commission of IUPAC.

The right of discoverers to suggest names was recognized in 1990 ([3] Section I-3.3.4):

Elements of atomic numbers greater than 103 are often referred to in the scientific literature but receive names only after they have been discovered. Names are needed for these elements even before their existence has been established and therefore IUPAC has approved a systematic nomenclature and series of three-letter symbols for the atoms of such elements ([3] Section I-3.3.5 and Table II, [4]).

The existence of this systematic nomenclature does not override the right of discoverers of new elements to suggest other names to IUPAC after their claim has been established beyond all doubt in the general scientific community.

These important quotations establish that, in the past: (1) the discoverers of new elements had the right to suggest names, (2) the IUPAC Commission on Nomenclature of Inorganic Chemistry was given the responsibility to examine such names and to conduct a public and private review process to determine their suitability before recommending one of them to the IUPAC Council for decision, and (3) priority of discovery could, but did not have to, be taken into account. As to the involvement of the IUPAC Commission on Atomic Weights, in 1949 it ceded the responsibility for naming the newly discovered elements 43, 61, 85, 87, 93-96 and elements 4, 41, 71, 72, 74, and 91, for which two or more names were current, to the Commission on Nomenclature for Inorganic Chemistry [5]. Furthermore, it could be established that in 1957 the Commission on Atomic Weights was not involved in the naming of elements 99-102 [6].

The following quotations are relevant to the selection of names:

Any new metallic elements should be given names ending in -ium. [2]

...Other elements recognised (or discovered) during the past three centuries were named according to various arbitrary associations of origin, physical or chemical properties, etc., and more recently to commemorate the names of some famous scientists. ([3] Section I-3.3.1) 
...It is desirable that the names of elements in different languages differ as little as possible. The names approved by IUPAC are based on considerations of practicality and prevailing usage. It is emphasised that the IUPAC selection carries no implication regarding priority of discovery. ([3] Section I-3.3.2)

This strategy and the guidelines formulated in 1947 should obviate the problem of multiple names from different laboratories for the same element. The responsibility for formally recommending a name to the IUPAC Council rests solely with the Inorganic Chemistry Division, which now follows the procedure outlined below for recommending a name to the IUPAC Council. This procedure differs from the IUPAC guidelines of 1947 in that priority of discovery will be assigned by a joint IUPAC-IUPAP Working Group [7-9], and that only the laboratory(ies) to which priority has been assigned is (are) allowed to recommend a name. The issue of priority applies only to newly discovered elements; if and when the priority of discovery of an already-named element is successfully challenged, then this element will not be renamed [10].

\section{CHOICE OF NAMES FOR NEW ELEMENTS}

In keeping with tradition, elements are named after

- a mythological concept or character (including an astronomical object);

- a mineral, or similar substance;

- a place or geographical region;

- a property of the element; or

- a scientist.

To avoid confusion in the literature, when a name has been in unofficial use for a particular element, but a different name is ultimately chosen for that element, then the first name cannot be transferred for use for another element. A case in point is element 105 for which the name hahnium has been unofficially used. Since the name dubnium was chosen for that element, hahnium cannot be used for another as yet unnamed element.

For linguistic consistency, the names of all new elements should end in "-ium".

\section{PROCEDURE FOR NAMING A NEW ELEMENT}

\subsection{Formal proposal of a name}

When the existence of a new element has been established beyond a reasonable doubt by a joint IUPAC-IUPAP Working Group, the discoverers and the IUPAC Inorganic Chemistry Division are informed. Within two months of receiving the report from the joint IUPAC-IUPAP Working Group, the President of the Inorganic Division will invite the discoverers to propose a name and symbol for consideration. The proposal must be accompanied by a justification of the choice. If no such proposal is received within six months after the invitation, the Inorganic Chemistry Division shall take the initiative to propose a name, which will be submitted to the IUPAC Council within two years of initiating the process. Similarly, when, in the case of a joint discovery, the laboratories involved cannot agree on a name and symbol within six months after the invitation, then the Inorganic Chemistry Division shall take the initiative.

\subsection{Examination by the Inorganic Chemistry Division and public review}

The Inorganic Chemistry Division will examine the proposed name and symbol for suitability and, if satisfied, take these through accepted IUPAC procedure [11]. This, briefly, consists of sending the rec- 
ommendation to 15 experts, officers of other interested commissions, the Interdivisional Committee on Terminology, Nomenclature and Symbols, the National and Regional Centers and interested individuals. IUPAP's opinion will also be sought. Should difficulties arise in any of these processes that make the proposed name unacceptable, then the Inorganic Chemistry Division will correspond with the laboratory or laboratories concerned to seek their agreement to any necessary changes or to an alternative name suggested for its consideration.

\subsection{Formal naming of the element}

When these processes are complete, the President of the Inorganic Chemistry Division forwards the Division's final recommendation for the name of a new element to the IUPAC Council for formal approval by the Union and publication in Pure and Applied Chemistry.

\subsection{Interim names}

Prior to and during the naming process, the element may be referred to by its atomic number, as in "element 118 " or by its provisional systematic name, "ununoctium". If a symbol is needed, the systematic, provisional three-letter symbol should be used ([3] Section I-3.3.5 and Table II, [4]).

\section{REFERENCES AND NOTES}

1. “...il exige une méthode constante de dénominations qui aide l'intelligence et soulage la memoire." L. B. Guyton de Morveau, "Sur les dénominations chymiques, la nécessité d'en perfectionner le système, et les règles pour y parvenir", Observations sur la Physique, sur l'Histoire Naturelle et sur les Arts 19, 370-382 (1782).

2. IUPAC. Commission de Nomenclature de Chimie Inorganique, "Tentative rules for inorganic nomenclature", in Comptes Rendus de la Dix-Septième Conférence, pp. 98-119, Stockholm (1953).

3. IUPAC. Nomenclature of Inorganic Chemistry, G. J. Leigh (Ed.), Blackwell Scientific Publications, Oxford (1990) (The Red Book).

4. J. Chatt. "Recommendations for the naming of elements of atomic numbers greater than 100", Pure Appl. Chem. 51, 381-384 (1979).

5. IUPAC. Commission des Poids Atomiques (Commission Report), in Comptes Rendus de la Quinzième Conférence, pp. 50-51, Amsterdam (1949).

6. IUPAC. Commission de Nomenclature de Chimie Inorganique (Commission Report), in Comptes Rendus de la Dix-Neuvième Conférence, pp. 93-93, Paris (1957).

7. A. H. Wapstra. "Criteria that must be satisfied for the discovery of a new chemical element to be recognized”, Pure Appl. Chem. 63, 879-886 (1991).

8. D. H. Wilkinson, A. H. Wapstra, I. Ulehla, R. C. Barber, N. N. Greenwood, A. Hrynkiewicz, Y. Jeannin, M. Lefort, M. Sakai (Transfermium working group of IUPAC and IUPAP). "Discovery of the transfermium elements. Part II: Introduction to discovery profiles. Part III: Discovery profiles of the transfermium elements", Pure Appl. Chem. 65, 1757-1814 (1993).

9. P. J. Karol, H. Nakahara, B. W. Petley, E. Vogt. "On the discovery of the elements 110-112", Pure Appl.Chem. 73, 959-967 (2001).

10. To avoid confusion, the suggestion by Paneth that elements be renamed after priority has been reassigned, is not followed. F. A. Paneth. "The making of the missing chemical elements", Nature 159, 8-10 (1947).

11. IUPAC Handbook 2002. http://www.iupac.org/reports/provisional/procedure.html. 